\title{
Feasibility of modulated electro-hyperthermia in preoperative treatment for locally advanced rectal cancer: Early phase 2 clinical results
}

\author{
S. H. YOU*, S. KIM \\ Department of Radiation Oncology, Wonju Severance Christian Hospital, Yonsei University Wonju College of Medicine, Wonju, Republic of \\ Korea \\ *Correspondence: ys3259@hotmail.com
}

Received June 23, 2019 / Accepted September 18, 2019

\begin{abstract}
Despite advances in the multimodal approach for rectal cancer, treatment-related side effects remain an important issue. From this perspective, a prospective trial was performed to investigate the feasibility of modulated electro-hyperthermia $(\mathrm{mEHT})$ as a concomitant boost to preoperative chemoradiation in locally advanced rectal cancer. Seventy-six patients with cT3-4 or cT2N+ rectal cancer were enrolled consecutively. Whole pelvic radiotherapy of 40 Gy was delivered with a 2-Gy daily fraction. mEHT with $13.56 \mathrm{MHz}$ frequency was boosted on a twice-weekly schedule concurrently with intravenous 5-fluorouracil or oral capecitabine. Surgical resection was planned 6-8 weeks after radiotherapy. The primary endpoint was the non-inferior treatment response rate assessed by pathologic downstaging and tumor regression. The secondary endpoint was acceptable toxicity during the preoperative treatment period. Sixty patients completed the planned treatment schedule. T- and N-downstaging was demonstrated in 40 patients (66.7\%) and 53 patients (88.3\%), respectively. Pathologic complete response was noted in 15.0\% (9 patients) and 76.7\% (46 patients) for T-stage and $\mathrm{N}$-stage, respectively. Total or near total tumor regression was observed in 20 patients $(33.3 \%)$. Grade $\geq 3$ toxicity occurred only in hematologic assessment; one case $(1.7 \%)$ of leukopenia and one case $(1.7 \%)$ of anemia. Sixteen patients $(26.7 \%)$ developed thermal toxicity, which was mostly Grade 1 (15 patients, 93.8\%). The relatively low dose of 40 Gy radiation showed comparable pathologic treatment outcomes and tolerable toxicity profiles with the addition of $\mathrm{mEHT}$, which may potentially replace part of the radiation dose in neoadjuvant treatment for rectal cancer.
\end{abstract}

Key words: rectal cancer, hyperthermia, neoadjuvant therapy

Preoperative chemoradiotherapy followed by total mesorectal excision is the treatment of choice for locally advanced rectal cancer [1]. An increase in radiation dose can enhance local tumor control, but the problem of increased toxicity cannot be overlooked.

The non-thermal effect of modulated electro-hyperthermia (mEHT) has been reported to be potentially helpful in loco-regional tumor control [2-4]. In particular, mEHT has therapeutic properties that do not stick to temperature alone $[2,5]$. Thus, it is expected that effective tumor control will be achieved while minimizing the heat-related side effects commonly seen in conventional hyperthermia. Since it is difficult to deliver sufficient radiotherapy without causing toxicity, mEHT can be added to limited-dose radiation in order to enhance the treatment response. Combining these methods, tumor control is expected to be effectively enhanced using a minimal dose of radiation for intestinal tissue, which has a low tolerance for radiation. Therefore, the assessment of a mEHT boost in preoperative chemoradiation is a timely attempt.

In the previous conventional hyperthermia studies, thermal burns were frequent especially during the treatment period $[6,7]$. Also, the temperature measurements for the tumor core were fundamentally limited due to invasiveness, which would require local anesthesia [8-12]. In most pelvic tumor treatments, temperature measurement was dependent on peri-tumor temperature, which is less accurate. Even at a relatively low temperature of $39^{\circ} \mathrm{C}$, a certain level of local therapeutic effect has been confirmed [13]. It is thus necessary to assess the treatment response focusing on the non-thermal effects out of the concept of temperature only.

As we identify the significance of mEHT, the non-thermal effects in clinical cases need to be examined to better understand the clinical significance of the treatment. This prospective phase 2 study was designed to assess the efficacy and safety of concurrent boost of $\mathrm{mEHT}$ in a preoperative 
chemoradiotherapy platform of non-aggressive radiation dose for locally advanced rectal cancer.

\section{Patients and methods}

Patient selection and pretreatment evaluation. Patients with histologically proven rectal adenocarcinoma requiring preoperative treatment were screened for eligibility. Inclusion criteria were age of 19 to 85 years, primary tumor located within $15 \mathrm{~cm}$ from anal verge, clinical T3-4 or N+ staged by magnetic resonance (MR) and computed tomography (CT) imaging, Eastern Cooperative Oncology Group performance status $\leq 2$, no prior pelvic irradiation, and proper function of the bone marrow, kidney, and liver. The major exclusion criteria were past disease history of the rectum, hereditary colorectal cancer, chronic inflammatory bowel disease, bowel stenosis, active infection, severe cardiac condition, pregnancy or nursing, simultaneously unresectable colon cancer, thermal hypersensitivity, too much subcutaneous fat expected to cause severe thermal toxicity in the abdominal and pelvic area.

This non-inferiority phase 2 trial was approved by the Institutional Review Board of Wonju Severance Christian Hospital (Approval number: CR313035). Before enrollment, written informed consent was obtained from all patients. This study is registered with ClinicalTrials.gov (study number NCT02546596).

The initial diagnosis was made by colonoscopy and biopsy. Clinical staging was done mainly by MR and CT imaging with additional transrectal ultrasonography or $18 \mathrm{~F}$-fluorodeoxyglucose positron emission tomography. Lymph node positivity was defined as a lymph node with a short axis length of $0.5 \mathrm{~cm}$ or more on MR or CT imaging. Laboratory tests included complete blood cell count, liver and renal function tests, carcinoembryonic antigen, and carbohydrate antigen 19-9.

Preoperative treatment schedule. A total dose of $40 \mathrm{~Gy}$ was delivered via a daily fraction of $2 \mathrm{~Gy}$, with five fractions per week. Either 5-fluorouracil/leucovorin or oral capecitabine was administered concurrently as systemic chemotherapy. 5-fluorouracil/leucovorin was injected intravenously with bolus for 3 days at the $1^{\text {st }}$ and $5^{\text {th }}$ week after initiation of radio-

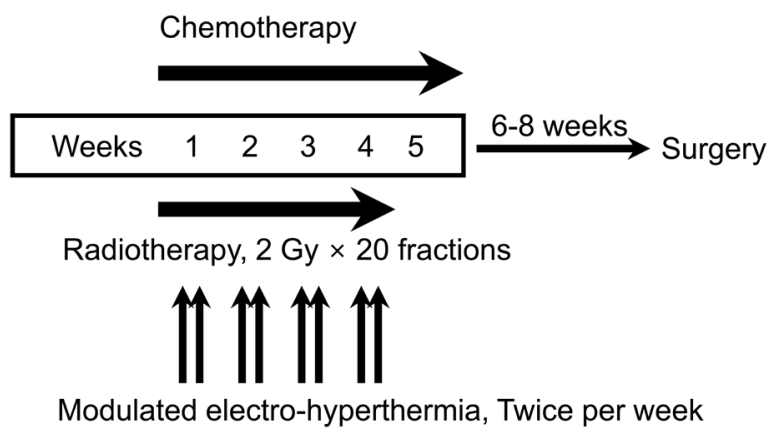

Figure 1. Overall preoperative treatment outline. therapy at doses of 400 and $20 \mathrm{mg} / \mathrm{m}^{2} /$ day for 5 -fluorouracil and leucovorin, respectively. Oral capecitabine was administered at a dose of $825 \mathrm{mg} / \mathrm{m}^{2}$ from the $1^{\text {st }}$ day of radiation during the virtual period of the conventional 28-fraction schedule. In addition to this slightly modified concurrent chemoradiation course, eight sessions of mEHT were combined twice weekly during scheduled radiation therapy. Typically, 6-8 weeks after the completion of the radiotherapy, curative resection with lymph node dissection was planned to be performed. In principle, sphincter preservation was intended but ultimately determined by the surgeon's discretion considering tumor location, sphincter function, or clinical response to the preoperative treatment. Transient conversion loop ileostomy or colostomy was performed in all patients. The overall preoperative treatment outline is illustrated in Figure 1.

Radiation therapy. Preoperative radiation was delivered by the technique of external beam X-ray from a linear accelerator (Elekta Synergy, Elekta, Stockholm, Sweden). The beam energy was 6-15 MV. Three-dimensional planning was performed following a planning CT (Aquillion LB, TSX-201A, Toshiba Medical Systems Corporation, Otawara, Japan) scan. Three- or four-field technique in the supine position was used depending on the location and the extent of the disease. The clinical target volume included the tumor, the mesorectum, the internal iliac nodes, and presacral nodes up to the sacral promontory level. During treatment, all patients underwent weekly medical examinations with a complete blood count check. The Pinnacle system (ADAC Laboratories, Milpitas, CA, USA) was used for treatment planning and tumor volume measurement.

Modulated electro-hyperthermia. mEHT was performed on a twice-weekly schedule during the radiotherapy period using $13.56 \mathrm{MHz}$ capacitive coupled device (EHY2000, Oncotherm GmbH, Troisdorf, Germany). All patients were treated in the supine position. A $30 \mathrm{~cm}$ diameter sized electrode was applied as an upper pole, whose center was located on the middle of the clinical target volume to cover the tumor and elective pelvic lymph node area. The duration of mEHT treatment was 60 minutes and the radiotherapy of that day followed immediately within one hour. At the beginning of treatment, the power was started at $100 \mathrm{~W}$ during the first $20 \mathrm{~min}$, maintained at least at $120 \mathrm{~W}$ for the next $20 \mathrm{~min}$, and fixed at $140 \mathrm{~W}$ for the last $20 \mathrm{~min}$. From the subsequent treatment session, the power was constantly fixed at $140 \mathrm{~W}$ if there were no toxicity problems. The patients' heat sense and tolerance were monitored in real time. The power was partially adjusted when heat-related discomforts were recognized. Separate temperature measurements were not performed considering the inherent limits of approach for primary tumors and lymph nodes.

Clinical outcome evaluation. The primary endpoint was preoperative therapeutic response assessed by pathologic downstaging and tumor regression grade. The secondary 
endpoint was maximum treatment toxicity during the preoperative treatment period. The initial clinical stage and the postoperative pathologic stage were determined according to the American Joint Committee on Cancer staging system, $7^{\text {th }}$ edition [14]. Downstaging was assessed by comparing these two stages. Tumor regression grade was evaluated by a standardized 5-point grading system described by Dworak et al. [15]. Treatment-related toxicities were assessed using the National Cancer Institute Common Terminology Criteria for Adverse Events (CTCAE), version 3.0 (NCI, Bethesda, MD, USA). The mEHT-related toxicity was evaluated separately according to the scoring system proposed by the Berlin group [6].

Statistical analysis. This study was a single arm, non-inferiority trial to evaluate whether the therapeutic response corresponding to conventional preoperative treatment could be achieved by a conservatively lower radiation dose plus mEHT boost. According to previous studies of similar contexts, a sample size of 65 patients was required to ensure a $40 \%$ tumor regression rate, a $10 \%$ margin of error, and a $90 \%$ confidence level [16]. Assuming a 10\% dropout rate, we planned to enroll a total of 72 patients in this study. Statistical analyses were mainly composed of descriptive contents and were performed using SPSS Statistics software version 23 (IBM, Armonk, NY).

\section{Results}

Patient enrollment and clinical characteristics. Finally, a total of 76 patients were enrolled due to a higher than expected rate of dropouts. The total recruitment period was from March 2014 to March 2017. Sixteen patients dropped out; 13 patients withdrew their consent before or immediately after the beginning of the treatment for personal reasons, and 3 patients changed their minds not to undergo surgery after completion of preoperative treatment. Ultimately, 60 individuals completed the trial and were included in the analysis. The patients had a median age of 59 (range 33-83) years and were predominantly male $(n=45,75 \%)$. The initial lymph node status was positive for all cases. The median clinical tumor volume was $52.7 \mathrm{~cm}^{3}$ (range $22.4-233.1 \mathrm{~cm}^{3}$ ). The patient characteristics before preoperative treatment are shown in Table 1.

All analyzed patients completed the preoperative treatment and curative surgery. The median overall radiotherapy treatment time was 27 days (range 24-43 days). The median total energy of mEHT was 3902 Joules (range 2704-4429 J). The operation performed was a low anterior resection for 50 patients $(83.3 \%)$ and abdominoperineal resection for 4 patients $(6.7 \%)$. There was one total exenteration and one intersphincteric resection case, which was associated with vaginal and cervical invasion of the primary tumor. One case of transanal excision was performed, though not originally planned, reflecting an excellent response to the preoperative treatment. In all other cases except this case, the median
Table 1. Patient characteristics before preoperative treatment $(n=60)$.

\begin{tabular}{|c|c|}
\hline Characteristic & Value \\
\hline \multicolumn{2}{|l|}{ Age (year) } \\
\hline Median (range) & $59(33-83)$ \\
\hline \multicolumn{2}{|l|}{ Sex } \\
\hline Male & $45(75.0 \%)$ \\
\hline Female & $15(25.0 \%)$ \\
\hline \multicolumn{2}{|l|}{ Pathologic diagnosis } \\
\hline Adenocarcinoma & $57(95.0 \%)$ \\
\hline Mucinous adenocarcinoma & $2(3.3 \%)$ \\
\hline Tubular adenocarcinoma & $1(1.7 \%)$ \\
\hline \multicolumn{2}{|l|}{ Differentiated } \\
\hline Well & $8(13.3 \%)$ \\
\hline Moderately & $49(81.7 \%)$ \\
\hline Poorly & $3(5.0 \%)$ \\
\hline \multicolumn{2}{|c|}{ Primary tumor location from the anal verge $(\mathrm{cm})$} \\
\hline$\leq 5$ & $23(38.3 \%)$ \\
\hline$>5, \leq 10$ & $29(48.3 \%)$ \\
\hline$>10, \leq 15$ & $8(13.3 \%)$ \\
\hline \multicolumn{2}{|l|}{ Primary tumor volume (ml) } \\
\hline Mean & $63.2 \pm 39.8$ \\
\hline Median (range) & $52.7(22.4-233.1)$ \\
\hline \multicolumn{2}{|l|}{ T stage $(\%)$} \\
\hline $\mathrm{T} 3$ & $46(76.7 \%)$ \\
\hline $\mathrm{T} 4$ & $14(23.3 \%)$ \\
\hline \multicolumn{2}{|l|}{ N stage (\%) } \\
\hline N1 & $28(46.7 \%)$ \\
\hline $\mathrm{N} 2$ & $32(53.3 \%)$ \\
\hline \multicolumn{2}{|c|}{ Carcinoembryonic antigen (ng/ml) } \\
\hline$\leq 5$ & $39(65.0 \%)$ \\
\hline$>5$ & $21(35.0 \%)$ \\
\hline Median (range) & $2.8(0.9-148.2)$ \\
\hline \multicolumn{2}{|l|}{ Carbohydrate antigen 19-9 (U/ml) } \\
\hline$\leq 37$ & $50(83.3 \%)$ \\
\hline$>37$ & $9(15.0 \%)$ \\
\hline Not evaluated & $1(1.7 \%)$ \\
\hline Median (range) & $11.8(0.6-869.1)$ \\
\hline
\end{tabular}

number of lymph node dissection was 16 (range 4-52). Factors associated with preoperative treatment and the surgical outcomes are displayed in Table 2.

Downstaging and tumor regression. After surgery, T-downstaging was observed in 40 patients (66.7\%). Regarding the lymph nodes, $\mathrm{N}$-downstaging occurred in 53 patients $(88.3 \%)$. The proportion of pathologic complete response for T-stage (ypT0) and $\mathrm{N}$-stage (ypN0) was $15.0 \%$ (9 patients) and 76.7\% (46 patients), respectively. The patient number of minimal, moderate, near total, and total regression grade for primary tumors was 9 (15.0\%), 31 (51.7\%), $11(18.3 \%)$, and $9(15.0 \%)$, respectively. The distribution of postoperative stages according to initial clinical stages is displayed in Table 3. 
Table 2. Factors associated with preoperative treatment and surgical outcome $(n=60)$.

\begin{tabular}{|c|c|}
\hline Characteristic & Value \\
\hline \multicolumn{2}{|l|}{ Overall radiotherapy period (day) } \\
\hline Mean & $27.8 \pm 2.7$ \\
\hline Median (range) & $27(24-43)$ \\
\hline \multicolumn{2}{|c|}{ Radiotherapy to surgery interval (day) } \\
\hline Mean & $52.0 \pm 7.2$ \\
\hline Median (range) & $52(41-70)$ \\
\hline \multicolumn{2}{|l|}{ Chemotherapy regimen } \\
\hline 5-fluorouracil/leucovorin & $4(6.7 \%)$ \\
\hline Capecitabine & $55(91.7 \%)$ \\
\hline Others & $1(1.7 \%)$ \\
\hline \multicolumn{2}{|l|}{ Total mEHT energy (Joule) } \\
\hline Mean & $3848.5 \pm 236.2$ \\
\hline Median (range) & $3902(2704-4429)$ \\
\hline \multicolumn{2}{|l|}{ Surgery type } \\
\hline Low anterior resection & $50(83.3 \%)$ \\
\hline Abdominoperineal resection & $4(6.7 \%)$ \\
\hline Hartmann's procedure & $3(5.0 \%)$ \\
\hline Total exenteration & $1(1.7 \%)$ \\
\hline Transanal excision & $1(1.7 \%)$ \\
\hline Intersphincteric resection & $1(1.7 \%)$ \\
\hline \multicolumn{2}{|l|}{ Proximal resection margin $(\mathrm{cm})^{*}$} \\
\hline Mean & $19.3 \pm 9.1$ \\
\hline Median (range) & $18(6-50)$ \\
\hline \multicolumn{2}{|l|}{ Distal resection margin $(\mathrm{cm})^{*}$} \\
\hline Mean & $2.2 \pm 1.8$ \\
\hline Median (range) & $1.9(0-8)^{\dagger}$ \\
\hline \multicolumn{2}{|c|}{ Circumferential resection margin $(\mathrm{cm})^{*}$} \\
\hline Mean & $0.59 \pm 0.62$ \\
\hline Median (range) & $0.3(0-1.9)^{\dagger}$ \\
\hline
\end{tabular}

*The cases of total regression were not included.

'The length for positive resection margin was defined as ' 0 '.

Toxicity. Treatment-related toxicities were easily tolerated. Hematologic toxicity of Grade 2 or higher was mainly found as leukopenia in 16 patients $(26.7 \%)$ and neutropenia in 6 patients $(10.0 \%)$. In the cases of anemia, Grade 2 or higher was observed in 7 patients (11.7\%). Genitourinary toxicity was generally low (only one Grade 2 or higher patient), which presented as non-infective cystitis related symptoms. Nineteen patients (31.7\%) experienced Grade 2 or higher gastrointestinal toxicities presenting as pelvic pain, nausea, or diarrhea. There was no Grade 3 or higher non-hematologic toxicity. For heat-related toxicity, the highest was Grade 2 in only one case. The details of toxicity distribution are shown in Table 4.

\section{Discussion}

This study was designed to confirm the role of mEHT boost in a reasonably low radiation dose setting. mEHT was expected to play a role in the preoperative treatment and
Table 3. Distribution of postoperative pathologic T- and N-downstaging according to each initial clinical stage $(n=60)$.

\begin{tabular}{lcc}
\hline & cT3 $(\mathbf{n}=\mathbf{4 6})$ & cT4 $(\mathbf{n}=\mathbf{1 4})$ \\
\hline ypT0 & $9(19.6 \%)$ & $0(0.0 \%)$ \\
ypT1 & $4(8.7 \%)$ & $1(7.1 \%)$ \\
ypT2 & $14(30.4 \%)$ & $5(35.7 \%)$ \\
ypT3 & $18(39.1 \%)$ & $7(50.0 \%)$ \\
ypT4 & $1(2.2 \%)$ & $1(7.1 \%)$ \\
\hline & cN1 (n=28) & cN2 (n=32) \\
\hline ypN0 & $25(89.3 \%)$ & $21(65.6 \%)$ \\
ypN1 & $2(7.1 \%)$ & $7(21.9 \%)$ \\
ypN2 & $1(3.6 \%)$ & $4(12.5 \%)$ \\
\hline
\end{tabular}

Table 4. Distribution of treatment-related toxicities $(n=60)$.

\begin{tabular}{lccccc}
\hline Toxicity & Grade 0 & Grade 1 & Grade 2 & Grade 3 & Grade 4 \\
\hline Leukopenia & 24 & 20 & 15 & 1 & 0 \\
Neutropenia & 43 & 11 & 6 & 0 & 0 \\
Anemia $^{*}$ & 44 & 9 & 6 & 1 & 0 \\
Thrombocytopenia & 58 & 1 & 1 & 0 & 0 \\
Genitourinary & 47 & 12 & 1 & 0 & 0 \\
Gastrointestinal & 20 & 21 & 19 & 0 & 0 \\
Heat-related $^{\dagger}$ & 44 & 15 & 1 & 0 & 0 \\
\hline
\end{tabular}

${ }^{*}$ Bleeding due to the disease itself seems to have some effect.

${ }^{\dagger}$ This was evaluated separately according to the scoring system proposed by the Berlin group [6].

our therapeutic combination resulted in favorable toxicity profiles with non-inferior treatment response compared to conventional methods in terms of downstaging, tumor regression grade, and pathologic complete response.

In gastrointestinal tract malignancy, including rectal cancer, limitations of toxicity are inevitable even with highprecision radiotherapy techniques such as the intensitymodulation method due to the vulnerability of bowel, the irradiation target itself $[17,18]$. For rectal cancer, radiotherapy may adversely affect anorectal function after total mesorectal excision, especially in patients with distal tumors. In previous studies on preoperative radiotherapy, poorer functional outcome was observed after low anterior resection with coloanal anastomosis [19-21]. In this respect, it is of great importance to minimize the radiation dose.

On the other hand, the possibility of decreased local control may arise by reducing the radiation dose. In a study comparing radiation dose levels by Wiltshire et al. [22], the higher doses seemed to show mildly better local control. However, this result is only partially due to higher radiation doses, because longer treatment periods resulted in more 5-fluorouracil doses as well. With respect to wound complications, high radiation doses were associated with more complications after surgery. In our study, a radiation dose of 40 Gy was applied to reduce complications as much as possible with the mEHT as an additional adjuvant treatment. Our dose level resulted in a generally acceptable toxicity 
Table 5. Previous preoperative thermoradiotherapy studies in which the pretreatment-to-pathological N stage profile tracking was available.

\begin{tabular}{|c|c|c|c|c|c|c|c|}
\hline References & $\begin{array}{l}\text { Patient } \\
\text { enroll- } \\
\text { ment }\end{array}$ & $\begin{array}{l}\text { No. of } \\
\text { patients who } \\
\text { received } \\
\text { preoperative } \\
\text { thermoradio- } \\
\text { therapy }\end{array}$ & $\begin{array}{l}\text { No. of cases with } \\
\text { positive pre- } \\
\text { treatment lymph } \\
\text { nodes among } \\
\text { preoperative } \\
\text { thermoradio- } \\
\text { therapy patients }\end{array}$ & Radiation dose & $\begin{array}{l}\text { Hyperthermia } \\
\text { machine }\end{array}$ & $\begin{array}{l}\text { No. of hyper- } \\
\text { thermia session }\end{array}$ & $\begin{array}{l}\text { ypN0 proportion } \\
\text { after preoperative } \\
\text { treatment among the } \\
\text { pretreatment lymph } \\
\text { node positive patients }\end{array}$ \\
\hline Rau et al., 1998 [6] & Phase 2 & 37 & 18 & 45 Gy / 25 times & BSD-2000 & $\begin{array}{l}\text { Once a week } \\
\text { (1-5 times) }\end{array}$ & $44.40 \%$ \\
\hline Maluta et al., 2010 [10] & Phase 2 & 76 & 41 & $\begin{array}{c}60 \mathrm{~Gy}(50 \mathrm{~Gy}+ \\
10 \mathrm{~Gy} \text { boost }) / \\
30 \text { times }\end{array}$ & BSD-2000 & $\begin{array}{l}\text { Once a week } \\
\text { (5 times) }\end{array}$ & $48.90 \%$ \\
\hline Tsutsumi et al., 2011 [26] & Retrospective & 93 & Unknown ${ }^{*}$ & $50 \mathrm{~Gy} / 20$ times & $\begin{array}{l}\text { Thermotron } \\
\text { RF-8 }\end{array}$ & $\begin{array}{l}\text { Once a week } \\
(2-5 \text { times })\end{array}$ & $\mathrm{N}$ downstaging: $58.1 \%^{\dagger}$ \\
\hline Kang et al., 2011 [25]" & Retrospective & 98 & 36 & $\begin{array}{l}\text { Group A: } 39.6 \\
\text { Gy / } 22 \text { times, } \\
\text { Group B: } 45.0 \\
\text { Gy / } 25 \text { times }\end{array}$ & $\begin{array}{l}\text { Cancermia } \\
\text { GHT-RF8 }\end{array}$ & $\begin{array}{l}\text { Twice a week } \\
\text { (1-11 times) }\end{array}$ & $\begin{array}{c}75.0 \% \text { (Group A: } 72.2 \% \\
\text { Group B: } 77.8 \% \text { ) }\end{array}$ \\
\hline Schroeder et al., 2012 [7] & Retrospective & 61 & 50 & $\begin{array}{c}50.4 \mathrm{~Gy} / 28 \\
\text { times }\end{array}$ & BSD-2000 & $\begin{array}{c}\text { Once or twice a } \\
\text { week (1-9 times) }\end{array}$ & $48.00 \%$ \\
\hline Kato et al., 2014 [27] & Retrospective & 48 & Unknown ${ }^{\star}$ & $50 \mathrm{~Gy} / 20$ times & $\begin{array}{l}\text { Thermotron } \\
\text { RF-8 }\end{array}$ & $\begin{array}{l}\text { Once a week } \\
(2-5 \text { times })\end{array}$ & $\mathrm{N}$ downstaging: $43.8 \%^{\dagger}$ \\
\hline Current study & Phase 2 & 60 & 60 & 40 Gy / 20 times & $\begin{array}{l}\text { Oncothermia } \\
\text { EHY-2000 }\end{array}$ & $\begin{array}{l}\text { Twice a week } \\
\text { (8 times) }\end{array}$ & $76.70 \%$ \\
\hline
\end{tabular}

${ }^{*}$ This specific number was not presented due to the characteristics of the study. ${ }^{\dagger}$ The proportion of total $\mathrm{N}$ downstaging was displayed as an alternative because the number of the patients whose $\mathrm{N}$ stage was changed from clinically positive to ypN0 was unknown. ${ }^{*}$ There was no toxicity report in this study and a maximum of 11 hyperthermia sessions were performed twice weekly for 4.5 - 5 weeks of radiotherapy. This suggests that hyperthermia was continued beyond the radiotherapy period. Therefore, the ypN0 proportion, which is similar to ours, is presented as a reference rather than a direct comparison.

pattern. This may be due to the relatively reduced radiation administration alongside mEHT, which allowed for acceptable anti-tumor effects without severe toxic side effects. Thus, considering the locoregional control and related toxicities, our radiation dose strategy seems to be valid.

Conventional hyperthermia has been shown to produce good treatment response and local control in rectal cancer treatment $[7,10,11,23,24]$. However, its application has been limited due to frequent heat-related toxicities. Typically, the number of hyperthermia sessions was restricted during radiotherapy. In a phase 2 study by Rau et al. [6], as much as $40.5 \%$ of patients experienced Grade 3 toxicities resulting in early cessation of hyperthermia. These findings were repeated in another retrospective study by Schroeder et al. [7], which found that $34 \%$ of patients discontinued treatment within the $1^{\text {st }}$ three hyperthermia sessions. Most of these toxicities and discomforts are related to temperature, directly or indirectly.

At this point, non-temperature dependent approaches such as $\mathrm{mEHT}$ are needed. As shown in the treatment of pelvic area by mEHT, treatment response by immune response and increase of blow flow can be expected with the peri-tumor temperature of $38.5 \pm 0.8^{\circ} \mathrm{C}$ [13]. For colorectal carcinoma, mEHT produced more tumor necrosis than conventional hyperthermia regardless of temperature [5]. In our study, the thermal toxicity was remarkably low and treatment response was excellent especially for pelvic lymph nodes, which are independent of temperature measurement.
This lymph node reactivity is known to be associated with the overall prognosis. According to Maluta et al. [10], the lower ypTN stage correlated with better survival after intensified preoperative chemoradiation and regional hyperthermia. In another relatively large-scale retrospective study, pN0 was highly associated with better survival regardless of the clinical $\mathrm{N}$ stage [25]. In our study, ypN0 from initially positive lymph nodes was shown in $76.7 \%$ of patients despite relatively low radiation dose. This ypN0 ratio is generally high compared with previous studies whose ratio was mostly lower than $50 \%$ (Table 5). In this regard, further study is needed on the immunological relevance of mEHT.

An important factor determining the utility of hyperthermia is its efficacy. Compared with other reports, our study was characterized by a uniformly high number of hyperthermia sessions for all patients (Table 5). This means that $\mathrm{mEHT}$ was potent enough to supplement the relatively insufficient radiation dose. In our study, a sufficient number of mEHT sessions were performed with little thermal toxicity, leading to satisfactory treatment response. The significance of our protocol may be explained by clinical confirmation of the non-thermal effect.

This study has somelimitations. First, temperature measurements were not performed in terms of the non-thermal effect at $<39^{\circ} \mathrm{C}$. This was due to the inherent inability to measure the temperature of the tumor itself, especially the lymph nodes. Second, the chemotherapy regimen was not uniform. 
However, this was considered acceptable because the heterogeneity of chemotherapeutic agents is generally known to have no difference in treatment outcome or toxicity grade for preoperative treatment. Third, the feasibility of mEHT was assessed without adequate control groups, which may be insufficient in terms of the comparison of therapeutic outcomes. Alternatively, for appropriate reference, we describe brief results of a conventional method without $\mathrm{mEHT}$ as follows: thirty-eight patients at the same hospital received 50.4 Gy of radiotherapy on a conventional schedule; general patient characteristics such as age, sex, pathology, and chemotherapy regimen were not statistically different from those in our current study group; initial clinical stage was relatively low in this non-mEHT group without statistical significance; ypT0 and ypN0 was seen in 4 patients (10.5\%) and 24 patients $(63.2 \%)$, respectively; despite no statistical significance, the non-mEHT group tended to show low proportion in downstaging, tumor regression, yp T0, and ypN0 compared to the current mEHT group (data not shown); based upon these findings, we are planning more systematic studies including proper control groups. We hope that these limitations will be complemented in future clinical trials.

In summary, non-inferior primary tumor regression and excellent lymph node response are sufficient to indicate the mEHT boosts as a useful option for rectal cancer treatment. Radiation was shown to be sufficiently supplemented by mEHT, with acceptable toxicity levels and feasibility in multimodality management. Therefore, mEHT can be combined as a boosting method with radiation. More active mEHT application needs to be attempted with various approaches to improve clinical outcomes from the perspective of non-thermal effects.

Acknowledgements: This work was supported by grants from the National Research Foundation (NRF) of Korea [grant number NRF2016R1D1A1B03935140] and a research fund from the HOSPICARE Co., Ltd. (Seoul, Korea) in the process of research ethics review, administrative procedure, and technical information collection.

\section{References}

[1] KYE BH, CHO HM. Overview of radiation therapy for treating rectal cancer. Ann Coloproctol 2014; 30: 165-174. https://doi.org/10.3393/ac.2014.30.4.165

[2] ANDOCS G, REHMAN MU, ZHAO QL, TABUCHI Y, KANAMORI $\mathrm{M}$ et al. Comparison of biological effects of modulated electro-hyperthermia and conventional heat treatment in human lymphoma U937 cells. Cell Death Discov 2016; 2: 16039. https://doi.org/10.1038/cddiscovery.2016.39

[3] MCDONALD M, CORDE S, LERCH M, ROSENFELD A, JACKSON M et al. First in vitro evidence of modulated electro-hyperthermia treatment performance in combination with megavoltage radiation by clonogenic assay. Sci Rep 2018; 8: 16608. https://doi.org/10.1038/s41598-018-34712-0
[4] HEGYI G, SZIGETI GP, SZASZ A. Hyperthermia versus oncothermia: Cellular effects in complementary cancer therapy. Evid Based Complement Alternat Med 2013; 2013: 672873. https://doi.org/10.1155/2013/672873

[5] ANDOCS G, RENNER H, BALOGH L, FONYAD L, JAKAB $\mathrm{C}$ et al. Strong synergy of heat and modulated electromagnetic field in tumor cell killing. Strahlenther Onkol 2009; 185: 120-126. https://doi.org/10.1007/s00066-009-1903-1

[6] RAU B, WUST P, HOHENBERGER P, LOFFEL J, HUNERBEIN $\mathrm{M}$ et al. Preoperative hyperthermia combined with radiochemotherapy in locally advanced rectal cancer: a phase II clinical trial. Ann Surg 1998; 227: 380-389. https://doi. org/10.1097/00000658-199803000-00010

[7] SCHROEDER C, GANI C, LAMPRECHT U, VON WEYHERN CH, WEINMANN $\mathrm{M}$ et al. Pathological complete response and sphincter-sparing surgery after neoadjuvant radiochemotherapy with regional hyperthermia for locally advanced rectal cancer compared with radiochemotherapy alone. Int J Hyperthermia. 2012; 28: 707-714. https://doi.org /10.3109/02656736.2012.722263

[8] OHGURI T, IMADA H, YAHARA K, MORIOKA T, NAKANO $\mathrm{K}$ et al. Radiotherapy with $8-\mathrm{MHz}$ radiofrequencycapacitive regional hyperthermia for stage III non-small-cell lung cancer: the radiofrequency-output power correlates with the intraesophageal temperature and clinical outcomes. Int J Radiat Oncol Biol Phys 2009; 73: 128-135. https://doi. org/10.1016/j.ijrobp.2008.03.059

[9] ANSCHER MS, LEE C, HURWITZ H, TYLER D, PROSNITZ LR et al. A pilot study of preoperative continuous infusion 5-fluorouracil, external microwave hyperthermia, and external beam radiotherapy for treatment of locally advanced, unresectable, or recurrent rectal cancer. Int J Radiat Oncol Biol Phys 2000; 47: 719-724. https://doi.org/10.1016/ S0360-3016(00)00473-9

[10] MALUTA S, ROMANO M, DALLOGLIO S, GENNA M, OLIANI $\mathrm{C}$ et al. Regional hyperthermia added to intensified preoperative chemo-radiation in locally advanced adenocarcinoma of middle and lower rectum. Int J Hyperthermia 2010; 26: 108-117. https://doi.org/10.3109/02656730903333958

[11] WUST P, RAU B, GELLERMAN J, PEGIOS W, LOFFEL J et al. Radiochemotherapy and hyperthermia in the treatment of rectal cancer. Recent Results Cancer Res 1998; 146: 175191. https://doi.org/10.1007/978-3-642-71967-7_16

[12] RAU B, WUST P, TILLY W, GELLERMANN J, HARDER C et al. Preoperative radiochemotherapy in locally advanced or recurrent rectal cancer: regional radiofrequency hyperthermia correlates with clinical parameters. Int J Radiat Oncol Biol Phys 2000; 48: 381-391. https://doi.org/10.1016/S03603016(00)00650-7

[13] LEE SY, KIM JH, HAN YH, CHO DH. The effect of modulated electro-hyperthermia on temperature and blood flow in human cervical carcinoma. Int J Hyperthermia 2018; 34: 953-960. https://doi.org/10.1080/02656736.2018.1423709

[14] American Joint Committee on cancer. Colon and rectum. In: Edge SB, Byrd DR, Compton CC, et al., editors. AJCC cancer staging manual. 7th ed. New York, NY: Springer; 2010. p. 143-164. 
[15] DWORAK O, KEILHOLZ L, HOFFMANN A. Pathological features of rectal cancer after preoperative radiochemotherapy. Int J Colorectal Dis 1997; 12: 19-23. https://doi. org/10.1007/s003840050072

[16] COCHRAN WG. Sampling techniques. 2nd ed. New York, NY: John Wiley and Sons; 1963.

[17] YEO SG, OH JH, KIM DY, BAEK JY, KIM SY et al. Preoperative short-course concurrent chemoradiation therapy followed by delayed surgery for locally advanced rectal cancer: a phase 2 multicenter study (KROG 10-01). Int J Radiat Oncol Biol Phys 2013; 86: 34-39. https://doi.org/10.1016/j. ijrobp.2012.11.018

[18] WEGNER RE, ABEL S, WHITE RJ, HORNE ZD, HASAN S et al. Trends in intensity-modulated radiation therapy use for rectal cancer in the neoadjuvant setting: a National Cancer Database analysis. Radiat Oncol J 2018; 36: 276-284. https:// doi.org/10.3857/roj.2018.00465

[19] LOOS M, QUENTMEIER P, SCHUSTER T, NITSCHE U, GERTLER R et al. Effect of preoperative radio(chemo)therapy on long-term functional outcome in rectal cancer patients: a systematic review and meta-analysis. Ann Surg Oncol 2013; 20: 1816-1828. https://doi.org/10.1245/s10434-012-2827-z

[20] FRITZMANN J, HUNERBEIN M, SLISOW W, GELLERMANN J, WUST P et al. [Influence of preoperative (hyperthermic) radiochemotherapy on manometric anal sphincter function in locally advanced rectal cancer]. Strahlenther Onkol 2004; 180: 281-288. https://doi.org/10.1007/s00066004-1173-x

[21] PARC Y, ZUTSHI M, ZALINSKI S, RUPPERT R, FURST A et al. Preoperative radiotherapy is associated with worse functional results after coloanal anastomosis for rectal cancer. Dis Colon Rectum 2009; 52: 2004-2014. https://doi. org/10.1007/DCR.0b013e3181beb4d8
[22] WILTSHIRE KL, WARD IG, SWALLOW C, OZA AM, CUMMINGS B et al. Preoperative radiation with concurrent chemotherapy for resectable rectal cancer: effect of dose escalation on pathologic complete response, local recurrencefree survival, disease-free survival, and overall survival. Int J Radiat Oncol Biol Phys 2006; 64: 709-716. https://doi. org/10.1016/j.ijrobp.2005.08.012

[23] LIANG H, ZHAN HJ, WANG BG, PAN Y, HAO XS. Change in expression of apoptosis genes after hyperthermia, chemotherapy and radiotherapy in human colon cancer transplanted into nude mice. World J Gastroenterol 2007; 13: 4365-4371. https://doi.org/10.3748/wjg.v13.i32.4365

[24] BARSUKOV YA, GORDEYEV SS, TKACHEV SI, FEDYANIN MY, PEREVOSHIKOV AG. Phase II study of concomitant chemoradiotherapy with local hyperthermia and metronidazole for locally advanced fixed rectal cancer. Colorectal Dis 2013; 15: 1107-1114. https://doi.org/10.1111/ codi.12281

[25] KANG MK, KIM MS, KIM JH. Clinical outcomes of mild hyperthermia for locally advanced rectal cancer treated with preoperative radiochemotherapy. Int J Hyperthermia 2011; 27: 482-490. https://doi.org/10.3109/02656736.2011. 563769

[26] TSUTSUMI S, TABE Y, FUJII T, YAMAGUCHI S, SUTO T et al. Tumor response and negative distal resection margins of rectal cancer after hyperthermochemoradiation therapy. Anticancer Res 2011; 31: 3963-3967.

[27] KATO T, FUJII T, IDE M, TAKADA T, SUTOH T et al. Effect of long interval between hyperthermochemoradiation therapy and surgery for rectal cancer on apoptosis, proliferation and tumor response. Anticancer Res 2014; 34 : 3141-3146. 